Session 3266

\title{
Teaching Assistants as a Catalyst for Composition Growth
}

\author{
Craig James Gunn \\ Michigan State University
}

\begin{abstract}
$\underline{\text { Abstract }}$
A procedure has been implemented to show the value of having graduate students act as the principle readers, evaluators, and graders of text produced in undergraduate mechanical engineering lab courses. Two years ago, the Department of Mechanical Engineering at Michigan State University shifted the responsibility of reading and grading both technical content and presentation quality of lab reports produced by

undergraduate juniors and seniors to the graduate teaching assistants in each required mechanical engineering lab. The new responsibility for these graduate assistants was begun in order to more efficiently address the enormous reading load that had arisen because of the interest in communication improvement in the department and the number of written reports that that interest had created. Although the reports were being read by a small group of teaching assistants for technical content, the composition feedback and grading was being handled by one individual. It was not only becoming physically impossible for one person to effectively read those quantities, but the quality of the comments and evaluations was beginning to suffer. It was therefore necessary to either reduce papers, cut feedback, or find another way to provide the needed comments that all writers need in order to improve their text production. The already existing body of teaching assistants was tapped to act as readers and evaluators. The issues regarding communication integrated into an engineering department, faculty support for the plan, preparation of the graduate students, orientation for the undergraduates who are impacted by the plan, and an evaluation of the process thus far will be addressed.
\end{abstract}

\section{Introduction}

Communication skill has always been one of the first things that is considered when deficiencies within engineering programs are evaluated. Over the past years many strategies have been undertaken to address these concerns. The Writing Across the Curriculum movement has focussed on making writing a part of every classroom. Writing Centers have taken the role of guides to writers who need an additional audience for their texts. Freshman composition courses have tried to get students involved with writing as they enter colleges and universities. And writing-intensive courses have been designated by an individual department to handle the writing experience for the department's students.

There is never a loss to find someone to say something about communication, from broad generalizations about speech patterns to highly specialized notions of exactly which word to use in a technical document. One of the most important realizations that we can ever make is that communication is part of our existence. From our first cries when we are born to the movements we make as we leave the world, we are communicating either to ourselves or to the world around us. Because this activity is so much a part of our lives, we cannot separate it from any of the other activities that we perform. Communication is, 
therefore, never an entity unto itself, and should never be considered as such. Ronald L. Miller and Barbara Olds in "A Model Curriculum for A Capstone Course in Multidisciplinary Engineering Design" (Journal of Engineering Education) report that at Harvey Mudd College, engineers enrolled in design classes must, as part of their design experience "interact with their clients in a professional manner and communicate with a variety of audiences (peers, faculty members, clients, etc.) orally and in writing. " It is, therefore, vitally important that engineering students realize the place of communication in their lives. This realization appears to be awakening in students because a survey conducted at The Colorado School of Mines (Miller, Olds 1993) shows that $\mathbf{9 5 . 3 \%}$ of students in multidisciplinary Senior Courses felt that "Good communication skills are an essential attribute of a professional design engineer. "In reality, without communication there is no engineering. The two must work together to provide the world with the expertise that engineering offers.

Thus, it is important that engineers constantly monitor their own written and spoken output and critically decide if it is correct, professional, and appropriate. Using whatever tools are available, writers can investigate the text to see how well their writing fits into those categories, On a higher level, outside help can provide greater expertise in making changes in text and spoken words. This pattern seems to be fairly prevalent in most schools: you write the text; you edit and proofread; and (if there is time) you get someone who can correct all the grammatical mistakes. The text is then handed in to sink or swim. In this process the art of communication seems to be an afterthought. It generally involves merely correcting the misplaced periods and commas, making subjects agree with their verbs, and performing a myriad of seemingly nonrelated items. When the text fails to earn a high grade, it is always the fault of the misused colon or the dangling participle. Technical knowledge, in the minds of engineers, has no connection to these grammar exercises and the presentation of knowledge. In fact, many engineers see it as a hindrance to the technical world. The need, then, is to provide a mechanism in which there is no discernible delineation between technical knowledge and the means to communicate it. Technical knowledge and communication skill must be used mutually to show the abilities and knowledge of the engineer.

Another factor to consider is the relationship between the writer and the reader. It is important to provide readers who relate to the writer. Peer editing of the text allows writers to see how a reader who is more closely attuned to their age and knowledge will react to what is written. In the past the professor has served as the solitary reader of undergraduate text. This provides a fairly narrow audience and, in many cases, does not provide the student with anything more than technical comments because many professors do not want to venture outside their own technical areas. These professors are uncomfortable with issues that they feel can only be adequately handled by English majors.

The problem, then, is how to create a greater awareness of communication, provide readership in the engineering area, and obtain feedback that will be valuable to the writer. It is with this problem in mind that graduate students in mechanical engineering were chosen to accomplish the above tasks.

\section{$\underline{\text { Rationale }}$}

Graduate students in MSU's Department of Mechanical Engineering have for many years been evaluating the technical content of reports in a variety of courses. Using their own expertise they read text, make appropriate comments on technical content, and suggest ways to improve the content material. The act of critiquing and correcting as a process is an integral part of the system. With this premise, the writer's technical knowledge and also ability to convey that knowledge needed to be judged together, not as two separate entities. The decision was made to give graduate students in the Department of Mechanical Engineering the responsibility for doing the combined evaluation. Some of the 16 mechanical engineering 
graduate teaching assistants involved in the project had already been evaluating undergraduate writing. The initial comments made by these teaching assistants gave a good indication of how the project would be accepted. "I already do it and have done it since the time that I started as a TA. " "I can't stop myself from commenting. I can't let something slide when it sounds bad or makes no sense. "I'm carrying on what others have told me." Perhaps graduate students are not usually asked to provide critiques on communication issues because they are engineers, and everyone knows that "engineers can't communicate." The reality is that our graduate students are highly competent individuals who have reached the graduate ranks because of their skills, both in the technical areas and in the ways that they communicate the technical material. They write, they speak, they teach, they provide an enormous body of information through their very existence as graduate students. It would be foolish indeed not to tap this source of valuable expertise and use it to improve communication skills at the undergraduate level. It is important, though, to take formal steps to place graduate students into the role of communication mentors.

\section{Implementation}

Four laboratory courses in the Department of Mechanical Engineering at Michigan State University are targeted in the communication effort: Heat Transfer, Vibrations, Controls, and Fluid Mechanics. Twentyfive teaching assistants will eventually grade both technical and composition areas. That is, the TA's will grade not only the technical abilities of undergraduates but also the methods that these students use to present that information completely, clearly, and competently to a selected audience, We pair graduate and undergraduate students for three reasons: graduate students interact with undergraduates on a much greater scale than faculty, undergraduate engineers have a tendency to listen to the comments of fellow engineers who have gone through the system, and graduate students benefit from the added focus on communication skill. Since most of the graduate students are working on either a thesis or a dissertation, the responsibility of making comments on undergraduate text should help the graduate students to look more intently at what they produce.

All of this commentary and grading cannot be done without a fair amount of preparation and careful monitoring. Faculty must be comfortable with the role being taken by graduate students, undergraduates must be clear as to what is being asked of them on text that they produce, and graduate students must receive enough training and support to make the process viable both for them and for the undergraduates to whom they are responsible.

With the above considerations in mind, faculty members gave ample suggestions to the number of assignments, the way in which reports would be handled, and the amount of preparation and support needed by their graduate students. Training sessions were planned to acquaint graduate students with the added responsibilities that they would encounter. Lastly, undergraduates were not excluded. The overall plan was presented before it is was implemented. Student concerns were addressed, and the semester's trial began with all parties cognizant of their role in the process. All parties involved were also apprised of the benefits of the plan. These included improved paper production, higher grades, and a closer link between graduate and undergraduate students.

Constant monitoring of the program, detailed instructions, support materials that include guides to areas of common concern, and an enormous amount of one-on-one contact hours for discussion have given a positive outlook to the future of utilizing ME graduate assistants in a new position of responsibility. The plan has been in place now for two years. Each semester begins with a orientation session for all teaching assistants. Concerns are aired, evaluation methods are discussed, and the upcoming semester is planned for 
the best experience for the undergraduates in each laboratory setting. Teaching assistants who feel uncomfortable with providing specific grammatical evaluations are given instruction in those areas. Support is provided for all teaching assistants in the form of double readings of the first rough drafts handed in by the students. These drafts receive feedback from both the teaching assistant and the Director of Communication. The director's comments help the teaching assistants to see the kinds of comments that they should be making, and the undergraduates receive the benefit of both technical and composition readings. The added value of having teaching assistants reading their own undergraduate students' work is that these readers have the greatest contact with the students. Teaching assistants monitor the labs, carry on technical conversations, and provide the necessary support for increasing the technical knowledge of the undergraduates. It is only logical that the graduate students be the first audience to whom the students write. This rapport between teaching assistants and undergraduates makes the process of implementing communication skill improvement a much easier task. It has been noted that the quality of the reports has improved because the act of communicating has become an engineering activity not an entity unto itself, Furthermore, the teaching assistants have noted that they have found their own work to have shown improvement. By becoming involved in both the technical and the composition evaluation, graduate students have become more comfortable in focussing on their own written production. Graduate students can be a most valuable catalyst in the effort to improve communication skill within an engineering department. For a little more effort with little increase in cost the value to any department may be immeasurable.

\section{$\underline{\text { Conclusions }}$}

Any methods that can be used to aid in the competence and experience level of engineers must be investigated. Every engineering department must look carefully at the jobs that are being done by professors, teaching assistants, and staff in order to formulate plans that incorporate more activities involving communication. We must utilize whatever means can be found to provide the best return for the time and money expended. It is also vital to pursue any resources that are under-utilized. Graduate assistants in an engineering major who become both the principal sources for comments on presentation and graders for technical reports are a means to more efficiently using an existing resource. Careful planning to provide a clear perspective of how the program works to faculty, graduate students, and undergraduates will generate a valuable experience for all involved.

\section{Bibliography}

Barbara Gross Davis, Tools for Teaching, San Francisco: Jossey-Bass, 1993.

Norbert Elliot et al. "The Assessment of Technical Writing: A Case Study," Journal of Technical Writing and Communication. Vol.24, No. 1, Winter 1994, p.9.

Ronald L. Miller and Barbara Olds, "A Model Curriculum for A Capstone Course in Multidisciplinary Engineering Design," Journal of Engineering Education, Vol.83,No.4 October 1993, pp. 311-323.

Peer commentary on Peer Review : A Case Studv in Scientific Quality_Control, New York: Cambridge University Press, 1982

\section{CRAIG JAMES GUNN}

Craig James Gunn is the Director of Communication for the Department of Mechanical Engineering at Michigan State University. He was educated at Michigan State University and he returned to the university in 1986 after teaching in the public school system for thirteen years. 